\begin{tabular}{|c|c|}
\hline & $\begin{array}{l}\text { International Journal of Trend in Scientific } \\
\text { Research and Development (IJTSRD) }\end{array}$ \\
\hline 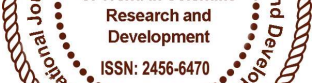 & International Open Access Journal \\
\hline 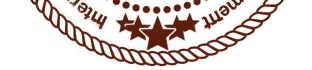 & ISSN No: 2456 - 6470 | www.ijtsrd.com | Volume - 2 | Issue - 2 \\
\hline
\end{tabular}

\title{
Traffic Congestion - Causes and Solution: A Study of Kota City
}

\author{
Harish Uniyal \\ Department of Civil Engineering, MAIIT, \\ Kota, Rajasthan, India
}

\author{
Dr. Hemlata Gandhi \\ Social Development And Infrastructure Manager, \\ Nagar Nigam, Kota, Rajasthan, India
}

\begin{abstract}
Kota city is the industrial city of Rajasthan and also major coaching hub of india. Kota city is swiftly moving towards being a "Smart City" but lack of parking space and road jam and encroachment on road is the biggest problem in Kota.To solve this problem we should take a step for road capacity expansion, improved road Infrastructure, restricting routs for auto rickshaw financial penalty to the traffic law brokers and application of fly over most importantly, proper traffic management system along with appropriate implementation of traffic rules is necessary to mitigate the problems of traffic congestion.
\end{abstract}

Keywords: Smart city, traffic congestion.

\section{INTRODUCTION}

Kota is situated on the banks of Chambal river known as the Charmanyawati in ancient vidas. Kota is an industrial and education city as well as hub of power plants as there are almost all kinds of power generation.These all facilities and employment attract people here. So the population is increasing day by day and when the population is increased, then the number of vehicle will be increased. Now Kota has an unenviable tag-that of the world's seventh most densely populated city with a population density of 12100 people per square $\mathrm{km}$ according to the World Economic Forum(WEF). Approximately $10.5 \%$ growth of vehicle in Kota every year. The number of total vehicles registered up to march 2016 is 7,10,676.In this paper we have discussed about the possible solutions for traffic congestion and parking facility in Kota.

\section{WHAT IS CONGESTION ?}

Traffic congestion occur when vehicles travel at slower speeds because there are more vehicles then the road can handle. This makes travel time longer, slower speed and increase vehicular queuing. This is also known as a traffic jam.

\section{WHAT ARE THE IMPACTS OF CONGESTION?}

Congestion involves queuing, slower speeds and increased travel times, which impose costs on the economy and generate multiple impacts on urban regions and their inhabitants. Congestion also has a range of indirect impacts including the marginal environmental and resource impacts of congestion, impacts on quality of life, stress, safety as well as impacts on non-vehicular road space users such as the users of sidewalks and road frontage properties.

\section{REASONS BEHIND TRAFFIC CONGESTION IN KOTA}

Inadequacy of traffic police

Traffic police in Kota city in adequate numbers. It is only 159 over the 11 lakh population.

\section{NARROW ROADS}

Streets of old Kota area are not that wide spread, due to illegal possession on the road they are getting narrow and becoming a reason behind traffic jam. So every possibility is there to expand the road as per their right of way to reduce traffic congestion. Moreover this will be less expensive and less time consuming due to land acquisition won't be required in this. 


\section{Illegal Parking}

Illegal parking on the road is the main reason behind serious traffic congestion on different part of the Kota city. For example, in gumanpura market ,shopping centre road, teenbatti to dadabari chota chauhraha, santosi nagar churaha mostly people parked their vehicle on road.

\section{Increasing number of population}

All the areas under Kota city are facing an increasing number of population which is a bad

indicator for the traffic management and this could be a vital reason behind traffic. Kota is coaching hub and approximately 1 lakh students take admission in coachings for engineering and medical entrance exams. Now Kota has an unenviable tag-that of the world's seventh most densely populated city with a population density of 12100 people per square $\mathrm{km}$ according to the World Economic Forum(WEF).

\section{Higher Purchasing power of the public}

Due to the higher purchasing power of the citizen ,easy vehicle loan facility, stallement payments, popularity of private transportation is increasing and but existing roads and highway are not supportive or changing according to the increasing number of vehicle. As a result vehicle congestion is increasing at an alarming rate.

\section{Improper planning of city development}

Development Plan has its long term city development planning. But that planning is not proper. Most of the time it is seen that some illegally ceased roadside land, but due to the vague development plan these kinds of movements are going in vain.

\section{Improper lane management}

Lane management is an important fact in managing the traffic in Kota city. Many types of the vehicles try to overtake the vehicles even in the single undivided road. This is the main reason that the city roads are unequipped with the lane dividers which divide the lane into incoming and outing traffic.

\section{Moving Cattles}

Sometime moving cattles is a big problem for traffic jam there are many incident when they are reason of road accident and cause of death and injury.

\section{SOLUTION OF TRAFFIC JAM}

\section{Strict lane management}

Different lanes for different types of vehicles should be marked on the roads and law i.e. financial penalty should be imposed to make the drivers maintain the lane discipline.

\section{Restricting routes for Rickshaw}

Rickshaw should not be allowed in all the routes of the city. R.T.O should take some responsibility to control the increasing number of rickshaws by imposing registration fee and legal documentation.

\section{Financial penalty to the traffic law breakers}

Government can take such strict step like imposing financial penalty on the law disobeying drivers. They should be made to dissude the drivers from certain Congestion-causing habit such as wrong overtaking, one way driving. Mobile court should be introduced to fine the truck drivers for disobeying traffic law and driving unfit truck. This kind of implication of law can mitigate the traffic jam in short run, but in long run all the people should be involved to create awareness and responsible to the society. Otherwise traffic jam solution is impossible.

\section{Supply and demand}

Congestion can be reduced by either increasing road capacity (supply) or by reducing traffic (demand) revealed that road capacity can be increased in a number of ways such as adding more capacity over the whole of a route or at bottlenecks, creating new routes, and improvements for traffic management. Reduction of demand can include, parking restriction, park and ride, congestion pricing, road space rationing, incentives to use public transport and introduction of e-education, e-shopping and home based working options will reduce the number of people traveling.

\section{Increasing and developing the manpower (Traffic police)}

As the city is running with inadequate amount of traffic police than required, so it is the need of the hour for the authority to increase the number of traffic police. This step will create some scope for employment also. Only recruitment is not enough, they should be trained up for the betterment of the traffic management.

\section{Road widening}

Road widening have been undertaken. However some research indicates that road widening provides only slight reductions in urban traffic congestion. 


\section{PROBLEM AND SOLUTION AS PER AREA OF CITY:}

\section{Bajariya market (Market nearby the railway} station): Fruit vendors and shopkeepers keep their goods and items in front of their shops which cover maximum portion of the roads and leave less space for driving vehicles which results in increased rate of parking problems like shortage of parking space and traffic jams.

Solution: All the fruit vendors should be transferred to the new fruit market made by UIT, Kota and impound the encroachments done by shopkeepers from the roads.

2. Nayapura: Two issues were found at this place. There is no space of parking for the shopkeepers as well as for the commuters, it arises the issue of shortage of parking. Secondly, NH12 and NH76 are passing through this places because of which it comes under accident prone areas of the Kota city.

Solution: Construct parking lot or complex in front of the Brij talkies for the shopkeepers and consumers, and the appropriate place for the mass transportation vehicles should be defined.

3. Arya samaj road near Rampura: It is called to be the rampart area of the Kota which was established in early days of Kota history. This is most visited place for the consumers and known as the main market of the city. Still it suffers from the acute shortage of parking and there is no space of parking for shopkeepers as well as consumers. Due to which, people park their vehicles in front of the shops.

Solution: We need appropriate space for parking complex in this locality, which can be created in area called Motor Market (Gaadi Khaana), where we have proposed space to construct a parking lot.

4. Gandhi Chowk: Because of exuberant activities of business, frequencies of private vehicles create more traffic at this place. This place has narrow roads and shortage of parking space which generally results in traffic jams.

Solution: Develop parking lot or complex on the nearby place where a school established by the Nagar Nigam, Kota which helps us in providing space for parking vehicles for shopkeepers and commuters.
5. Chaar Khamba and Agrasen Market: Similar situation as that of Gandhi Chowk occurs in Rampura.

Solution: Develop parking complex at the place occupied by old unused building of old police quarters which will help in solving the problem of parking at this place.

6. Old Vegetable market (Sabzimandi): Similar problems as that of at Agrasen Market and Gandhi Chowk is faced at this place. Roads are narrow because of encroachment done by shopkeepers.

Solution: Shift this market to a new place and develop the parking lot in place of this market, which will provide space of parking for the residents, shopkeepers and consumers.

7. Shripura Market: There is no space of parking in this busy market.

Solution: Give the proper shape to the circle (Subhash Circle) located at this place which will help us in providing the space for parking.

8. Gumanpura Market: It is the core area of Kota city or it can be said that it is the place where you can find all branded showrooms.

Solution: Provide space for parking in the arena of Multipurpose School. It will solve the problem of parking and flow of traffic in the Gumanpura market.

9. Chhawani (under the over bridge): A lot of public and private vehicles cross by this place and which creates the situation of traffic jam.

Solution: Remove the encroachment in front of the LIC building and provide the space for constructing a parking lot at that place. Take a charge ,public for the vehicles parking under the Flyover.

10. Aerodrome Circle: It is very busy and crowded circle in the city having lots of vehicle pressure. No space for appropriate parking for shopkeepers, commuters and other mode of transportation vehicles which create the situation of traffic congestion.

Solution: Use sliplane and reduced a diameter of circle. 
11. Commerce College Road (at Maitri hospital): It is the one way road and it has a lot of big private hospitals, but there is no an appropriate place for the parking because of this commuters face the parking problem.

Solution: The sewer channels in front of Maitri and Sudha hospital can be covered to solve the parking problem at this place.

12. Satosi Nagar Chuhara: In this chauhara ,many shopes are there and auto rikshaw are stopped in main road so in a evening there are facing a problem of road jam .the other reason is, there is near a sajimandi so many peoples are parked their vehicles on the road.

Solution: Shift the sabimandi to other place. Take an action and fine against vehicle owner.

\section{CONCLUSION}

Traffic congestion is a global as well as local problem. All over the world, the prime cause of traffic congestion is on street parking. In Kota city now traffic congestion is a common issue like Mumbai, delhi. Different infrastructural and managerial projects are granted for reducing traffic jam. However in Kota city this type of policy is not addressed yet.

Traffic congestion constraints can be ameliorated by embarking on various strategies such as road capacity expansion, improved road infrastructures, restricting routes for Rickshaw, financial penalty to the traffic law breakers and application of Fly over. Most importantly, proper traffic management system along with appropriate implementation of traffic rules is necessary to mitigate the problems of traffic congestion in smart city Kota.

\section{REFERENCES}

1) Haribandhu Panda\& RS Pundir, "Problems and possible solutions for better traffic management: A case study of Vadodara- Ahmadabad section of national highway eight", Research Paper 19, August 2002, Institute of Rural Management, Anand(IRMA).

2) Manuj Darbari Sanjay Medhavi and Abhay Kumar Srivastava, "Development of effective Urban Road Traffic Management using workflow techniques for upcoming metro cities like Lucknow (India ) ", International Journal of 